\title{
Systematic Risk Coefficient and Sentiment: Peculiarities of Sentiment Affected Companies in US Tourism Industry
}

Kirill Angel* and Carlota Menendez Plans

Department of Tourism, Autonomous University of Barcelona, Spain

\begin{abstract}
This paper investigates the role that investor sentiment plays in asset pricing and risk measure, research will focus on the relationship that came from the point that a firm stock level is a derivative not only of a fundamental rational environment but at the same time is a part of a human mental being, reflecting personal sentiment and group narratives. In the current paper we incorporate behavioral sentiment variables into beta model, analyzing cluster peculiarities of sentiment dependent companies in US tourism industry, finding out which type of companies has strong regression between beta and sentiment. We found that the level of regression between systematic risk coefficient and sentiment is dependent on period of sentiment, it is stronger during high and low sentiment period. We also found that high-low period of sentiment affects differently on companies from different clusters and sentiment affected companies have low level of financial stability.
\end{abstract}

Keywords: Financial; Market; Mathematical models

\section{Introduction}

Efficient market hypothesis (EMH) remains in the core of academic attention for many years, researchers tend to shed the light to the routes of profitability increase for both private and institutional investors. Degutis and Novickyte [1] notices that there is a multiple reasons for such research and one of them is that CFOs and executives will be able to increase value of companies through actions based on the understanding of market efficiency.

Despite the efficient market hypothesis were the central pillars of finance since the 1960s, nowadays the significance of the EMH moved to a subject of discussion. Shiller [2] in his work named the EMH to be "half-true". While EMH can easily and fully describe general movements on the stock, we can still find some patterns in prices, which EMH fails to explain.

Following the idea that markets are essentially rational, modern academic finance built the initial model of market rationality which was called the capital asset pricing model (CAPM) being developed by Sharpe [3] and Lintner [4]. Such model allows to quantify risk and provides a methodology for expected return on equity estimation basing the model of portfolio choice designed by Markowitz [5]. But of course the model has its limitation appeared from the assumptions as risk adverse and focus on the mean and variance of a single period return.

The CAPM considers beta $(\beta)$ as a systematic risk, it reflects a numeric measurement of the fluctuations of a stock against changes in the overall stock market. Beta measures the responsiveness of a stock's price to changes of the overall stock market. In the paper of Damodaran [6] we can find a relationship between risk level and cost of capital. $\mathrm{He}$ shows that the cost of capital is strictly determined by systematic risk or beta.

While beta is currently under consideration we can pretend it to be still a valid objective and systematic equity risk measure, which allows to calculate the required minimum return of capital of publicly traded shares. Classical Capital Asset Pricing Model (CAPM) defines the variables, which influence on systematic risk coefficient $(\beta)$ from EMH point of view, remembering the market and traders being rational and leaving no space for emotions and sentiment existing on the market which narrow and limit the appliance of the theory.
But we should remember that it is usual for a mankind to rely not only on ideal mathematical modeling but on emotions which are part of natural motions, so far we can conclude that our psychological aspects push us for actions which are completely or partially led by sentiment. At the same time such sentiment reflects incorrect probability beliefs about market events, and lead by primary emotions. We don't construct any mathematical models or forecasts we just follow our instincts. For instance we could overestimate the positive results due to excessive optimism or underestimate unfavorable. Shefrin [7] says that such situation will lead to an upward tendency of expected value.

Current research will focus on the relationship that came from the point that a firm stock level is a derivative not only of a fundamental rational environment but at the same time is a part of a human mental being, reflexing personal sentiment and group narratives.

This paper investigates the role that investor sentiment plays in asset pricing. While behavioral finance continue to be a relatively new approach in the field of financial research, one of the important areas that researchers have managed to develop is the role that noise traders play in determining asset prices [8]. One of the prominent examples of behavioral incorporation into classical pricing model theory is behavioral SDF (b-SDF) developed be Hersh Shefrin.

In the recent paper we will try to incorporate behavioral sentiment variables into beta model analyzing cluster peculiarities of sentiment dependent companies.

\section{Literature Review}

In this part we will provide a brief outlook of the literature relevant

*Corresponding author: Kirill Angel, Department of Tourism, Autonomous University of Barcelona, Spain, Tel: + 349358111 11; E-mail: kirillangel@gmail.com

Received September 10, 2018; Accepted November 14, 2018; Published November 21, 2018

Citation: Angel K, Plans CM (2018) Systematic Risk Coefficient and Sentiment Peculiarities of Sentiment Affected Companies in US Tourism Industry. Bus Eco J 9: 378. doi: 10.4172/2151-6219.1000378

Copyright: $(2018$ Angel K, et al. This is an open-access article distributed under the terms of the Creative Commons Attribution License, which permits unrestricted use, distribution, and reproduction in any medium, provided the original author and source are credited. 
to the research, from the general theory point of view, and from exact research topics.

Most of the risk incorporated asset valuation models have appeared on the base of the efficiency theory. For example the CAPM model consider the systematic risk as the single risk factor presenting a microstructural aspect. However, it is obvious that there are huge number of other risk factors which companies face today. Some of these factors are bankruptcy risk, currency risk, supplier risk, etc.

As a result, a lot of research was done in the field of identifying the most robust and predictive risk factors following different hypothesis bounded by the available data from traded stocks. A deep research was done by Fama and French [9], they found that value and size are the most robust factors outside of market risk to explain the return of stocks. The scientists published their results on these factors in 1992 at first and later have continued to define findings. The same way, in order to develop an extension of the original CAPM, Acharya and Perderson [10] have inserted a recent risk factor called systematic risk adjusted to liquidity risk.

Nevertheless, at the same time the study of the literature reveals the current concern about the relationship between equity risk and available information. Proof of this interest is the recent works of [1115] etc. Arfaoui and Abaoub [11] studied how the local equity depends on the influence of inflation, local investment, budget surplus, financial development and trade openness risk factors. Morelli [12] explores the relationship between security returns and beta, size and book-tomarket equity. Driessen et al. [13] developed a new econometric model to estimate the risk and return of an asset using cash flow. Boz et al. [14] analyze whether Financial Reporting Standard (IFRS) has affected determinants of stock risk. Babenko et al. [15] provided results that economic variable correlated with the history of idiosyncratic shocks would help to explain expected returns.

Another group of existing literature, which justifies the interest of our research, consists of articles that analyze the determinants of equity risk for a sample of companies in the tourism sector. Here are several recent papers: [16-21]. We must admit that going down to a sector level can provide more accurate results on risk assessment. It should be remembered that the country and industry are important factors of the share valuation process if we want to explain the systematic equity risk. Engle et al. [22] studied how country and industry contribute to the systematic risk of the European financial. Mar-Molinero [23] showed that the crisis of 2008 affect the main determinants of risk. Growth, business productivity, liquidity and the size of the business, shifted to the core factors for risk explanation.

Systematic risk levels vary depending the sector of economy [24]. Engle et al. [22] in their paper underlined the importance to differentiate between country and industry for proper share valuation process inside of systematic risk model. In the following paper we continue research of Angel et al. [25] using the set of companies from US tourism industry. Hospitality sphere seems to be very promising because it covers more than 3\% of US GDP and plays important role in economic power together with reflexing economic trends. Necessity to combine finance and hospitality was claimed by Park and Jang [26]. Some recent papers analyze the determinants of equity risk for a sample of companies in the tourism sector: $[14,16,21,25]$.

The other field of knowledge appeared on the frontier of social psychology and finance in parallel to efficient market theory. Selden [27] wrote Psychology of the Stock Market. The prominent book developed the idea that most of the stock movements are derivative of personal and institutional mental attitude. In 1956, the US psychologist Leon Festinger introduced a concept of cognitive dissonance, it was a new notion in the field of social psychology [28]. Pratt [29] distinguish risk aversion, and utility function as a proportion of total assets. Tversky and Kahneman [30] developed a judgmental heuristic, when an individual analyze the frequency or probability depending its availability. In 1974 they described representativeness, availability and anchoring as three main heuristics used under uncertainty. They also present a critique of expected utility theory. In another important paper a framing concept was introduced. Kahneman et al. [31] reported some experiments on loss aversion, showing that such actions as far as endowment are preferable in the market with possibility to learn, so they conclude loss aversion and endowment are the core pillars of preferences. Daniel et al. [32] developed a model of security market in which they introduced a concept of overconfidence and self-attribution, showing that such mental attitude leads to under-and overreactions. Shleifer [33] published "Inefficient markets: An introduction to behavioral finance", a quality book that considers behavioral finance as special and complete field of knowledge. Shefrin [34] wrote "Beyond Greed and Fear", an excellent book on behavioral finance and the psychology of investing.

The framework for such research is the asset-pricing model described. And some later Baker and Wurgler [35] reported that relationship between realized returns and characteristics such as size and $\mathrm{B} / \mathrm{M}$ could be controlled by the sentiment. Shefrin [7] proposed a behavioral approach to asset pricing through behavioral SDF model based on research of behavioral capital asset pricing theory [36]. Antoniou et al. [37] provided the research to validate the CAPM through the sentiment possible influence. A wide range of literature appeared on the fringe of sentiment variables, stock fluctuations and risk measurement at the beginning of XXI century. Bandopadhyaya and Jones [38] developed a special index using the public data and grouping firms to represent the whole market in one index, he found that sentiment fluctuations appeared of news or mental attitude change could explain a significant part of changes in the stock index. Baker and Wurgler [35] made a well-known index using a "top down" approach for stock market modeling, they consider sentiment to have external source. They provided the clear evidence to sentiment measurement and showed that sentiment fluctuations affect stock market and separate firms. Hwang and Salmon [39] described the routes of beta herding (moving together in the same direction) when the market is moving smoothly. On the other side they noticed that crises push investors to seek out fundamental value rather than herd. The herding gave us the reason to differentiate the periods of sentiment to have correct effect and impact on asset return.

Chang et al. [40] provided similar research in the field of idiosyncratic risk which has positive correlation with overconfidence; the result was equal both for individuals and market level. Moreover, he found that controlled overconfidence could decrease the positive trend. Hachicha and Bouri [41] in his research analyzed the stock return and showed that sentiment changes and fluctuations have a great correlation with return. Ling et al. [42] used vector autoregressive models and provided an evidence for positive relation between investor sentiment and returns in the field of estate markets.

Finter et al. [43] developed a sentiment indicator for Germany and checked how it can help to explain the level of return. He combined some wide-spread sentiment variables and constructed index based on principal component analysis. Boido and Fasano [44] reconcile the sentiment and defined it as a wish to speculate, they found positive link 
between sentiment and speculation. It is definite that different stocks have different level of sentiment sensitivity, and the riskiest to arbitrage are the stocks which are difficult to value. Antoniou et al. [37] considered how sentiment mediate the profitability of price momentum strategies. They found that profit increases within optimistic periods. He fined that small investors are frightened to sell loosing stocks during optimistic wave. Using a standard Fama and French approach they distinguished that beta is positively significant during pessimistic period. The most important finding is that the rational models are dominant and better work in the market only when the number of rational agents prevail. Stambaugh et al. [45] analyzed the number of anomalies and sentiment effect on it.

Chung et al. [46] analyzed two types of economic state, he found that expansion state allows the sentiment to have strong predictive evidence, at the same time returns of portfolio cannot be explained by sentiment during recession and it becomes insignificant. Antoniou et al. [47] explore how beta is priced within different emotional periods. He reported that beta is positively priced if the sentiment is negative and reflects pessimistic state in the market. It was also found that negative pricing is followed by optimism state but the evidence is not strong. Chow and Klein [48] considered sentiment sensitive and insensitive stocks and provided information that insensitive stocks stochastically dominate over sentiment sensitive stock.

Brilliant and key researcher in the field of behavioral finance, Shefrin [49] using data from 1999 to 2014 provided the proof to negative correlation between size and risk judgement, on the contrary having positive relation to beta and book-to-market equity. Fong and Toh [50] showed that investor desire to poses stock with high lottery payoff is dependent on investor sentiment. Boido and Fassano [44] used a CAPM model researching connection of sentiment and return, explaining the difference between standardized market models and real asset pricing behavior.

Some other recent papers which defend the relevance of the following research are Yu and Yuan [51], who provided the evidence of positive link between conditional variance within negative sentiment state and expected return. Stambaugh et al. [45] analyzed a number of anomalies and provided a robust evidence of anomaly strengthening during high sentiment period. Mclean and Zhao [52] analyzed the sensitivity between investments, sentiment and financial information. Jurek and Stafford [53] considered downside market risk rate of return related to alternative type of investment. Habib and Hasan [54] researched the effect of overvaluation on business strategy and future stock-price crash risk. It was cleared that innovative strategies are under risk concerning possible future stock-price crash.

The other papers which underline the cross-relation between risk management, sentiment and applied methodology are works of Deeney et al. [55] who made a novelty attempt to make a sentiment index for crude oil market showing that sentiment affects risk not only financial markets but a commodity market also. Authors developed variables similar to Baker et al. [56] sentiment index but relevant to oil market. Using principal component analysis they demonstrated that sentiment influence WTI (West Texas Intermediate) and BRENT markets. Antoniou et al. [57] provided a regression analysis and found a very important implication of sentiment variable. They had indicated that company management can use CAPM to provide capital budgeting decisions only in pessimistic periods, but not for optimistic ones. It was assumed to happen because periods of optimism attract equity investment of unsophisticated and overconfident traders in risky shares, but during the state of pessimism, noise trading is lower, so that traditional beta pricing prevails. This paper highlights the interrelation between behavioral finance, sentiment and risk management and underline the possibility to use beta as the measurement of risk. Frugier [58] made a comparative analysis of forty-six shares from EURO STOXX using State Street Investor Confidence Index as sentiment variable and he found an evidence that portfolios with integrated sentiment are less risky and have higher return, so far taking into account the imperfect rationality of investors such result can help to establish a better models for market analysis which should not be bounded by optimistic or pessimistic state, but should be improved and complexified.

Basing the previous papers on the topic of sentiment and risk we will conduct our research to measure correlation between sentiment coefficient and beta.

As far as beta is a systematic risk and it reflects a numeric measurement of the fluctuations of a stock against changes in the overall stock market we can conclude that beta measures the responsiveness of a stock's price to changes of the overall stock market. Cederburg and O'Doherty [59] found the positive link between market volatility and conditional beta, while having negative between beta and premium.

By this, we will find which companies are more subjected to sentiment. We will be able to understand which company has a risk measure, which is mostly affected by sentiment, and who fluctuate mostly because of sentiment changes. So-called sentiment affected risk.

The more beta of the stock is correlated to sentiment - the more sentiment affects the evaluation of the risk of the stock by investor.

Sentiment coefficient and company's data are taken for American market to continue research of Angel et al. [25] in which the beta and available information were analyzed. In the current research we will analyze the peculiarities of the companies with high regression between beta and sentiment, so called sentiment affected companies through regression and cluster analysis, defining the specific of such companies.

Claessens et al. [60] define one of the peculiarities of firm specific weakness is high level of leverage as the part of firm financial instability. Berkmen et al. [61] proved that countries with more leveraged domestic financial systems, stronger credit growth, and more short-term debt suffer a larger effect on economic activity. We hypothesis that companies with low level of financial stability have stronger dependence between beta and sentiment, so far reflecting sentiment situation on market. From methodological point of view, cluster analysis will provide us the basis to differentiate the group of companies depending level of regression between beta and sentiment. Hollenstein [62] grouped firms into clusters which are similar in terms of a large set of innovation indicators and identified five clusters to be analyzed having completely different configuration. Tola et al. [63] proved the analytical importance of cluster analysis using it for portfolio optimization technique.

Taking into account the conducted literature review we can establish two hypotheses contrasting our paper:

H1: High-low period of sentiment influence on the value of systematic risk coefficient $(\beta)$.

H2: Relationship between systematic risk coefficient $(\beta)$ and sentiment is stronger in the group of companies with low level of financial stability comparing to the full sample of companies.

Our study offers new findings to several branches of literature, it contributes to a branch of behavioral finance that studies how 
mispricing affects real investment and to the growing literature on risk management, providing additional information for the behavioral versus neoclassical finance debate. We contribute to such specify topics as: sentiment effect on cost of capital and investor risk measure.

Our research provides additional data to the above mentioned fields of research, opens new topics for discussion and future development. It will help to build new questions for future: does the high sentiment push the beta to grow? If beta and sentiment are positively correlated, does it mean that fluctuation of company stock converge to market fluctuation in the period of positive sentiment, does traders avoid risk and tend to herding in that period?

We would like the researches to dive deep into the direction of the questions mentioned above, trying to understand better the specific of stock market risk evaluation. Our paper developed as following: in chapter 2 we provide the model and methodology, in chapter 3 we discuss results and chapter 4 continues with conclusion, limitation and future research routes.

\section{Methodology}

In this chapter we provide the methodological part of our research, following the structural logic, at first, we explain and provide the beta calculation, later we estimate sentiment through the construction of compound sentiment index, on the next step we study relation between sentiment and systematic risk and finally provide cluster analysis to understand the economic and financial characteristic of companies which show the significant relation between beta and sentiment.

\section{Systematic risk $(\beta)$ estimation}

To continue our previous research we conduct the methodological part based on the data used before, we proceed with sample of 79 American firms in the tourism industry, specifying sectors of Arts, Entertainment, Recreation and Accommodation and Food Services. We proceed to use period of years 2004-2013. Data have been obtained from Bureau Van Dijk database (the Orbis data base) for all company accounting information and from sites, www.bea.gov (Bureau of Economic analysis), www.bls.gov (Bureau of Labor Statistics) y www. ec.europa.eu/eurostat (Eurostat) for the macroeconomic data and www.stoxx.com and www.yahoo.finance data for stock indices and rates. Beta $(\beta)$ is the dependent variable of the study (the systematic equity risk of the sampled companies) is estimated by the following regression model:

$$
R_{i t}=\alpha_{i}+\beta_{i y} R_{\mu t}+\mu_{i t}
$$

\section{Where:}

i identifies the number of companies in the sample 1......79

$t$ represents the number of data used to estimate the beta, 360 days

y represents the number of scanned fiscal years, 2004...2013

$\mathrm{R}_{\mathrm{it}}$ is the return on stock $\mathrm{i}$ at a time $\mathrm{t}$

$\beta_{\text {iy }}$ identifies the beta of stock $i$ in year $y$

$\mathrm{R}_{\mu} \mathrm{t}$ identifies profitability of the market portfolio in period $\mathrm{t}$

$\mu_{\mathrm{it}}$ is the random regression residual, assuming hope $=0$ and constant variance

Beta is estimated monthly for each of the 79 companies, from daily returns. Dow Jones Industrial Average Index is the market portfolio used to estimate betas, from which daily returns is calculated according to the equation:

$\operatorname{Ln}[\mathrm{It} / \mathrm{It}-1]$

On which:

It is the value of the index at the end of the day $\mathrm{t}$

It-1 is the value of the index at the end of day t-1

In the following Table 1, we can see the descriptive statistics of the beta calculation.

Descriptive statistics demonstrate the characteristics of the analyzed sample:

1) Total number of observations is 58 vs. 72 in full scope, as far as 14 companies were chosen to be not relevant due to lack of data and its representativeness.

2) We observed 10 years and received 6960 monthly beta values

3) Average beta is 0,865 and median is 0,901 that means that most of the companies in the sample are less volatile than the market.

4) Highest beta is 12,713 and lowest is $-35,747$, that shows some extremums during period under consideration

5) Quantile data shows that $13.5 \%$ of observations were negative providing inverse relation to market volatility, showing opposite direction to the market.

\section{Compound sentiment index construction}

To analyze the relation between beta and sentiment, we need to construct a sentiment index in SPSS software as far as no pure sentiment measure reflect all market peculiarities at the exact time, but using sentiment index we approximate to the real matter of state.

In the last years have appeared a number of studies on the influence of investor sentiment on stock market. But there is no decision on investor sentiment measure. There are mostly 2 main categories: downtop (survey-based and direct measure of sentiment) and top-down (market sentiment indices) [35].

A top-down approach is calculated based on stock market transaction activities. For example, Baker and Wurgler [35] develop a composite index of sentiment (S) based on six proxies for sentiment: NYSE share turnover, the closed end fund discount, the equity share

\begin{tabular}{|l|c|}
\hline Frequency: & HIGH \\
\hline No. of years & 10 \\
\hline No. of companies & 58 \\
\hline No. of observations & 6960 \\
\hline Central tendency: & 0.865 \\
\hline MEAN & 0.901 \\
\hline MEDIAN & \\
\hline Variation & 12.713 \\
\hline Highest var. & -35.747 \\
\hline Highest var. & 1.351 \\
\hline ST.DEV & \\
\hline Position & 1.405 \\
\hline PERCENTILE 75\% & 0.901 \\
\hline PERCENTILE 50\% & 0.383 \\
\hline PERCENTILE 25\% & 0.000 \\
\hline PERCENTILE 13.5\% & \\
\hline
\end{tabular}


in new issues, the number and average first-day returns on IPOs and the dividend premium. The other reliable indexes are VIX (CBOE volatility index), put-call ratio etc. From the other side all down-top investor sentiment indices are gathered from household or expert reports, answers and opinions. The respondents need to express their prediction of stock market or any future feelings on the prospect of the economy or personal financial expectations on monthly or weekly base. Good example of survey-based sentiment indices are all kinds of Consumer Confidence indexes like Conference Board Consumer Confidence Index, the Investors Intelligence sentiment index or the University of Michigan Consumer Sentiment Index which will be used in our research [55].

We must admit that the selection of sentiment index or surveys are mainly matter of personal chose, it is an arbitrary work to capture different information on the purpose of the study and data. This thesis employs both survey-based and market-based investor sentiment indices to reflect as much sentiment peculiarities as possible.

From a top-down approach we rely on sentiment definition appeared in Baker and Wurgler [35]. The idea is that most of the down-top approaches reflect mass psychological effects while the topdown approach aggregate sentiment and its effects to market returns and individual stocks. Every year the information is published on the Jeffrey Wurgler web page http://people.stern.nyu.edu/jwurgler/.

He provides a monthly sentiment index which is constructed on a base of the six proxies: trading volume as measured by NYSE turnover; the dividend premium; the closed-end fund discount; the number and first-day returns on IPOs; and the equity share in new issues.

The second top-down index was chosen to be CBOE Volatility Index (VIX) which is based on the S\&P 500 Index (SPX) and estimates expected volatility by averaging prices of puts and call. The data was taken from: http://www.cboe.com/vix.

Kadilli [64] proposed to use a down-top sentiment variables for USA confidence index from OECD as the most used index data to measure field sentiment within final consumers and business, including business, consumer confidence index composite leading indicator, and also Michigan university confidence index and American association individual investor index.

Using these indicators will help us to use partial down-top approach reflecting individual and mass psychology.

More precisely the indexes from OECD database (http://www. oecd.org):

CLI: The composite leading indicator (CLI) provides early signals of business cycle changes through the vibration of the economic activity.

BCI: The business confidence index (BCI) is comparing enterprise answers and opinions against normal state of production and expectations.

CCI: The consumer confidence index (CCI) is comparing household answers and opinions against normal state of future expectations and individual plans.

In the following diagram 1 , we can see the fluctuations of Consumer Confidence Index, which showed the negative inclination from 2003 to 2009 and then light growth from 2009 to 2013 (Figure 1).

UMCSent: The University of Michigan sentiment index based on household phone surveys about overall economic situation.
AAII: American Association individual investor index shows bullish-bearish-neutral feeling of individual investors about stock market in 6 months.

Below, in diagram 2, we observe the example of the weekly diagram on American Association individual investor index, showing the percent of responses to measure market in 6 months questioned in April 2018 (Figure 2).

To be able to measure and compare AAII index to the other indexes, we decided to give weight " 1 " to bearish, " 0 " to neutral and "- 1 " to bearish voice in AAII data, transferring answers into scale datum.

In the current research we use PCA (principal component analysis) to produce a linear combination of the proxies. The first principal component is the linear combination of the proxies which hold the maximum variance compared with other linear combinations subject to normalization. Deeney et al. [55] found that prices in the oil industry are under pressure by the sentiment constructed with the help oil market proxies combined into index.

We follow the research of Wold et al. [65] who described the technique of principal component analysis, he postulates that data should be centralized and normalized before being used. To prepare data we conducted a mean correction by subtracting a mean from each variable to centralize (eqn. (3)) and at the next stage we normalized each data variable by dividing variables to its standard deviation by which we avoid scaling and weight issues (eqn. (4)).

$$
\begin{aligned}
& m_{j}=\left(x_{1 j}+\ldots . .+x_{I j}\right) / I \\
& s_{j}=\sqrt{\sum_{i=1}^{I}\left(x_{i j}-m_{j}\right)^{2} / I}
\end{aligned}
$$

\section{CCI (2004-2013)}

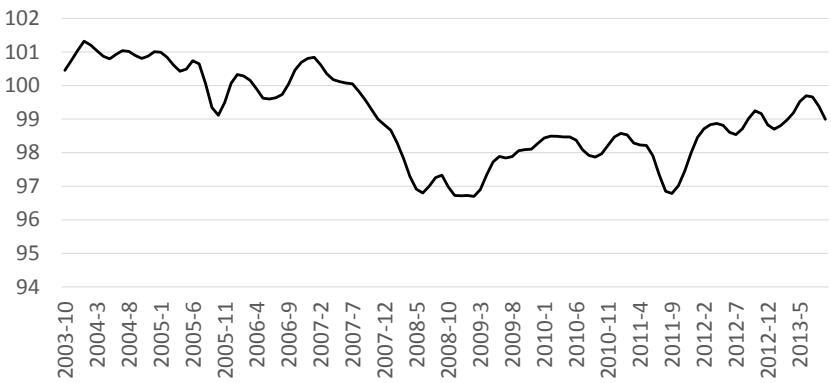

Figure 1: CCl index 2004-2013.

\section{AAll 4/18/2018}

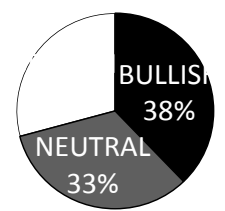

BULLISH $\square$ NEUTRAL $\square$ BEARISH

Figure 2: AAll index week 18 April 2008 
The full equation for auto-scaling is below, we subtract a mean from each variable and divide by its standard deviation:

$\widetilde{x_{i j}}=\left(x_{i j}-m_{j}\right) / s_{j}$

On which:

$\mathrm{X}_{\mathrm{ij}} \quad$ is the value of each variable $\mathrm{t}$

$m_{j} \quad$ is mean of data set

$s_{j} \quad$ is the standard deviation of data set

Abdi and Williams [66] provide a methodology to receive proper results for principal component analysis in SPSS. We need to follow the main assumptions of statistical methodology, we must confirm the existence of linear relationship between all variables, check the sampling adequacy and make a test of sphericity to have suitable data for reduction.

Below, in Table 2 we provide the correlation coefficients between variables to check linear relationship between all sentiment variables.

The data in Table 2 shows that:

a) There is small correlation between top-down (S, VIX) and down-top approaches, $\mathrm{S}$ correlate from 0.118 to 0.409 comparing to confidence indexes.

b) Consumer Confidence index (CCI) highly correlate to University of Michigan index by 0.981

c) Volatility index (VIX) has negative correlation to all other indexes

d) American Investor index (AAII) had lowest correlation to all other indexes

e) Business confidence index (BCI) is highly correlated to all index, but very low correlation to consumer index (CCI). If we look at the diagram 3, we can conclude that at the stage of 2008 crisis, business was late to expect it and earlier reveal growth comparing to consumers. It is an interesting observation, which push us to define business to be more optimistic comparing to consumers. And we tend future researches to analyze such phenomenon (Figure 3).

According to correlation matrix and due to interest of research we avoid CCI index and use only UMCSENT index, we keep other indexes for PCA to achieve compound result reflecting both top-down and down-top approaches.

Following Leech et al. [67], the assumptions for principal component analysis include sample size issues, we need to determine factorability of the data set matrix at whole. We make the KaiserMeyer-Olkin (KMO) measure of sampling adequacy and Bartlett's test of sphericity to have suitable data for reduction.

Sampling adequacy is done through the Kaiser-Meyer-Olkin (KMO) measure of sampling adequacy for the overall data set. They provided 0.5 (value for $\mathrm{KMO}$ ) as minimum, values between $0.7-0.8$ acceptable, and values above 0.9 are perfect. Looking at the Table 3, the KMO measure is 0.707 , which is close of 0.8 and therefore can be completely accepted. Bartlett's test of sphericity is provided to have

$\mathrm{CCl}$ and $\mathrm{BCl}(2004-2013)$

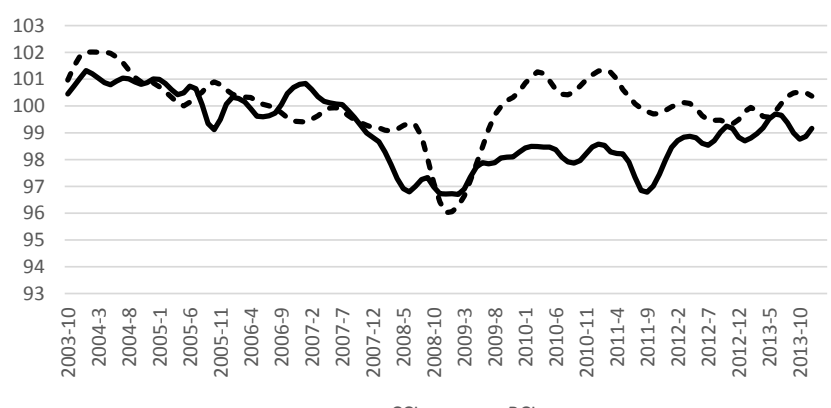

Figure 3: $\mathrm{CCl}$ and $\mathrm{BCl}$ cross section in 2004-2013.

\begin{tabular}{|c|c|c|c|c|c|c|c|c|}
\hline & & $\mathbf{s}$ & $\mathrm{CCl}$ & $\mathrm{BCl}$ & CLI & UMCSENT & AAll & VIX \\
\hline \multirow[t]{3}{*}{$\mathrm{s}$} & Pearson Correlation & 1 & $0.409^{* \star}$ & 0.118 & $0.707^{* *}$ & $0.391^{* *}$ & 0.033 & $-0.515^{\star *}$ \\
\hline & Sig. [2-tailed] & & 0.000 & 0.192 & 0.000 & 0.000 & 0.714 & 0.000 \\
\hline & $\mathrm{N}$ & 123 & 123 & 123 & 123 & 123 & 123 & 123 \\
\hline \multirow[t]{3}{*}{$\mathrm{CCl}$} & Pearson Correlation & $0.409^{* *}$ & 1 & $0.575^{\star *}$ & $0.657^{* *}$ & $0.981^{* *}$ & $0.395^{* *}$ & $-0.712^{\star *}$ \\
\hline & Sig. [2-tailed] & 0.000 & & 0.000 & 0.000 & 0.000 & 0.000 & 0.000 \\
\hline & $\mathrm{N}$ & 123 & 123 & 123 & 123 & 123 & 123 & 123 \\
\hline \multirow[t]{3}{*}{$\mathrm{BCl}$} & Pearson Correlation & 0.118 & $0.575^{\star *}$ & 1 & $0.630^{* *}$ & $0.553^{\star *}$ & $0.444^{* *}$ & $-0.682^{* *}$ \\
\hline & Sig. [2-tailed] & 0.192 & 0.000 & & 0.000 & 0.000 & 0.000 & 0.000 \\
\hline & $\mathrm{N}$ & 123 & 123 & 123 & 123 & 123 & 123 & 123 \\
\hline \multirow[t]{3}{*}{ CLI } & Pearson Correlation & $0.707^{* *}$ & $0.657^{* *}$ & $0.630^{\star *}$ & 1 & $0.633^{\star *}$ & $0.291^{* *}$ & $-0.750^{* *}$ \\
\hline & Sig. [2-tailed] & 0.000 & 0.000 & 0.000 & & 0.000 & 0.001 & 0.000 \\
\hline & $\mathrm{N}$ & 123 & 123 & 123 & 123 & 123 & 123 & 123 \\
\hline \multirow[t]{3}{*}{ UMCSENT } & Pearson Correlation & $0.391^{* *}$ & $0.981^{* *}$ & $0.553^{\star *}$ & $0.633^{* *}$ & 1 & $0.393^{\star *}$ & $-0.705^{\star \star}$ \\
\hline & Sig. [2-tailed] & 0.000 & 0.000 & 0.000 & 0.000 & & 0.000 & 0.000 \\
\hline & $\mathrm{N}$ & 123 & 123 & 123 & 123 & 123 & 123 & 123 \\
\hline \multirow[t]{3}{*}{ AAll } & Pearson Correlation & 0.033 & $0.395^{\star *}$ & $0.444^{* *}$ & $0.291^{* *}$ & $0.393^{\star *}$ & 1 & $-0.381^{* *}$ \\
\hline & Sig. [2-tailed] & 0.714 & 0.000 & 0.000 & 0.001 & 0.000 & & 0.000 \\
\hline & $\mathrm{N}$ & 123 & 123 & 123 & 123 & 123 & 123 & 123 \\
\hline \multirow[t]{3}{*}{ VIX } & Pearson Correlation & $-0.515^{* *}$ & $-0.712^{\star *}$ & $-0.682^{* *}$ & $-0.750^{* *}$ & $-0.705^{\star \star}$ & $-0.381^{* *}$ & 1 \\
\hline & Sig. [2-tailed] & 0.000 & 0.000 & 0.000 & 0.000 & 0.000 & 0.000 & \\
\hline & $\mathrm{N}$ & 123 & 123 & 123 & 123 & 123 & 123 & 123 \\
\hline
\end{tabular}

Table 2: Correlations of variables for PCA. 
suitable data for reduction. From the Table 3, we can see that the Bartlett's test of sphericity is significant (0.00). That is, significance is less than 0.05 . In fact, it is actually 0.00 , i.e. the significance level is enough to reject the null hypothesis. This means that correlation matrix is not an identity matrix (Table 3 ).

Following Wold et al. [65] we demonstrate the values in Table 4, which indicate the proportion of each variable's variance that can be explained by the principal components (Table 4 ).

Obviously, the procedure of constructing the sentiment index is not perfect and has no universal rule, however, but the advantage of constructing a composite index for sentiment versus examining the component series separately is that the composite index allows the relative strength of the components to change over time. To be able to produce a compound index we continue approach developed by Wold et al. [65]. In Table 5 we check for relevance and select the first component variation to represent compound sentiment index (Table 5).

Regarding the results obtained in the Table 5, we can construct a compound index using the coefficients in the column 1 of Table 5. The PCA model provide the following compound sentiment index:

$$
\begin{aligned}
& C I=1,185 * S+0,161 * B C I-0,076 * C L I-0,136 * \\
& U M C S e n t+0,063 * A A I I+0,244 * V I X
\end{aligned}
$$

In Figure 4 we show the fluctuation of compound index within period of consideration, we see that CI was negative during world financial crisis of 2008 and neutrally positive within other periods (Figure 4).

To identify whether a particular formation period is optimistic or pessimistic we use an eqn. (6), where we calculate a weighted rolling average of the compound index (WMA(CI)) of the sentiment level for

\begin{tabular}{|l|c|}
\hline Kaiser-Meyer-Olkin Measure of Sampling Adequacy & 0.707 \\
\hline Bartlett's Test of Approx. Chi-Square Sphericity & $4,47,571$ \\
\hline df & 15 \\
\hline Sig. & 0.000 \\
\hline
\end{tabular}

Table 3: KMO and Bartlett's test. the three months prior to the end of the formation period. On the back of the approach developed by Antoniou et al. [47], we give a weight of three to sentiment in the prior month, two to the one in the month prior to that and one to the month three months prior to the current month. A formation period is classified as optimistic (pessimistic) if the three-month rolling average ending in month $t$ belongs to the top (bottom) $30 \%$ of the three-month rolling average sentiment. At the end we have 3 periods of high, low and neutral sentiment.

$$
\mathrm{WMA}(\mathrm{CI})=3^{\star} \mathrm{CI}_{\mathrm{t}-1}+2^{\star} \mathrm{CI}_{\mathrm{t}-2}+1^{\star} \mathrm{CI}_{\mathrm{t}-3} / 6
$$

Below, we present the Figure 5 reflecting high-neutral-low period of weighted moving average compound sentiment index. Most of the time sentiment kept in neutral period, it was high before crisis 2008 and low after it, in 2011 we also found signals of high sentiment. WMA (CI) provide us more accurate data comparing to pure compound index showed on Figure 5.

\section{Regression between beta and compound sentiment index}

For the research we apply the regression approach which was used in Cornell et al. [68].

We apply the following model:

$\beta_{i, t}=\alpha_{0}+\sum_{f=1}^{C I} \alpha_{f} C I_{i f t}+\varepsilon_{t}$

Where:

$\beta_{\mathrm{it}} \quad$ identifies beta as dependent variable of firm $\mathrm{i}$ in month $\mathrm{t}$

$a_{f} \quad$ is the correlation coefficient of each indicator

$\mathrm{CI}_{\text {ift }}$ is independent variables from compound sentiment index

$\varepsilon_{\mathrm{t}} \quad$ is error for each firm in any period.

We applied linear regression analysis for a set of data, analyzing each pair of regression results.

At first stage we conducted a regression analysis for full range of

\begin{tabular}{|c|c|c|c|c|c|c|}
\hline \multirow[t]{2}{*}{ Component } & \multicolumn{3}{|c|}{ Initial Eigenvalues } & \multicolumn{3}{|c|}{ Extraction Sums of Squared Loadings } \\
\hline & Total & $\%$ of Variance & Cumulative \% & Total & $\%$ of Variance & Cumulative $\%$ \\
\hline 1 & 3.520 & 58.668 & 58.668 & 3.520 & 58.668 & 58.668 \\
\hline 2 & 1.146 & 19.094 & 77.762 & 1.146 & 19.094 & 77.762 \\
\hline 3 & 583 & 9.724 & 87.486 & & & \\
\hline 4 & 419 & 6.988 & 94.474 & & & \\
\hline 5 & 227 & 3.788 & 98.262 & & & \\
\hline 6 & 104 & 1.738 & 1.00 .000 & & & \\
\hline
\end{tabular}
data, and then divided it for high, low and neutral period according to methodology from Antoniou et al. [47]. We regress beta to both

\begin{tabular}{|c|c|c|c|c|c|c|}
\hline & \multicolumn{6}{|c|}{ Component } \\
\hline & 1 & 2 & 3 & 4 & 5 & 6 \\
\hline S & 1.185 & .214 & -.127 & .070 & -.432 & -1.326 \\
\hline $\mathrm{BCl}$ & 161 & 1.419 & -167 & -143 & -.580 & -1.003 \\
\hline CLI & -076 & -169 & -128 & -24 & -145 & 2.300 \\
\hline UMCSENT & -136 & -187 & 1.368 & -126 & -431 & -225 \\
\hline AAll & 0.063 & -202 & -167 & 1.112 & -106 & -21 \\
\hline VIX & 244 & 341 & 269 & 76 & -1.811 & 082 \\
\hline
\end{tabular}

Table 4: Data reduction test for PCA.

Table 5: Component score coefficient matrix. 
Compound index and to weighted moving average index to check for the better model response. The full results are provided in Appendix 1. We noticed that some companies are better react to CI while the other better react to WMA. As far as some companies are better regress to weighted moving average sentiment index and others to direct sentiment index, we made a weighted average for both indexes given a weight of $50 \%$ to weighted moving average compound index (WMA (CI)) and 50\% to pure compound index (CI), by this we average the result and decrease the possibility of mistake due respect to calculation method. The full results could be found in Appendix 2.

In the following Table 6, we provide the descriptive statistics of the regression part of the research referring to $\mathrm{R}^{2}$ (Table 6).

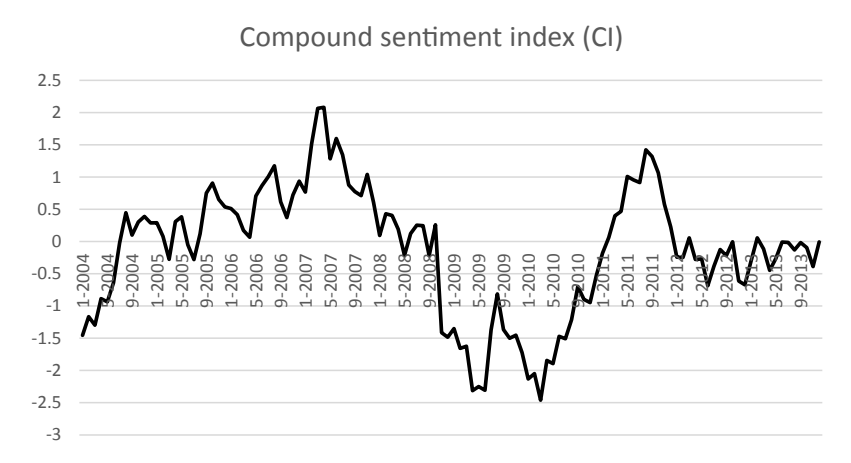

Figure 4: Compound index 2004-2013.

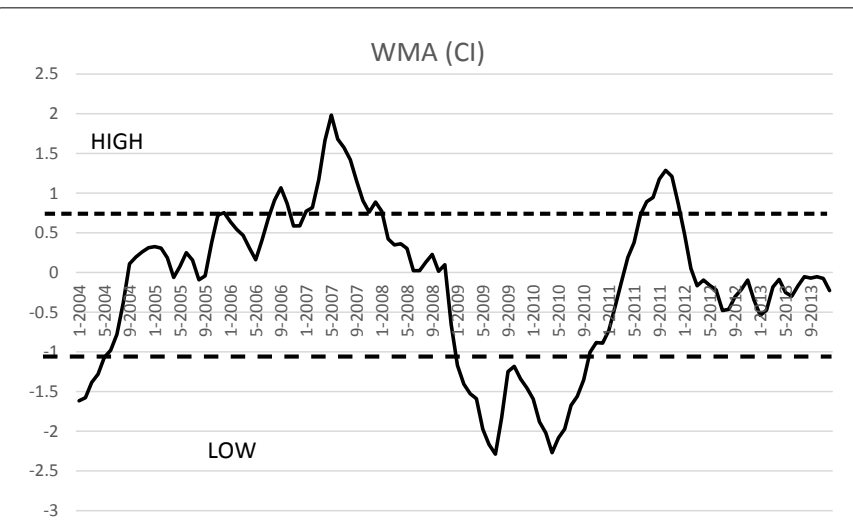

Figure 5: Weighted moving average compound index 2004-2013.

\begin{tabular}{|l|c|c|c|c|}
\hline & \multicolumn{4}{|c|}{ Sentiment period } \\
\hline Frequency & HIGH & NEUTRAL & LOW & FULL \\
\hline COUNT & 58 & 58 & 58 & 58 \\
\hline Central tendency & & & & \\
\hline MEAN & $4.8 \%$ & $2.3 \%$ & $4.8 \%$ & $3.6 \%$ \\
\hline MEDIAN & $2.7 \%$ & $1.0 \%$ & $3.8 \%$ & $2.1 \%$ \\
\hline Variation & & & & \\
\hline Highest var. & $25.0 \%$ & $16.0 \%$ & $20.0 \%$ & $20.0 \%$ \\
\hline ST.DEV & $4.9 \%$ & $3.0 \%$ & $4.7 \%$ & $4.5 \%$ \\
\hline Position & & & & \\
\hline PERCENTILE 75\% & $6.9 \%$ & $3.4 \%$ & $6.1 \%$ & $4.6 \%$ \\
\hline PERCENTILE 50\% & $2.7 \%$ & $1.0 \%$ & $3.8 \%$ & $2.1 \%$ \\
\hline PERCENTILE 25\% & $1.4 \%$ & $0.4 \%$ & $1.3 \%$ & $0.5 \%$ \\
\hline Significance & & & & \\
\hline Significance F. & $<0.05$ & $<0.05$ & $<0.05$ & $<0.05$ \\
\hline
\end{tabular}

Table 6: Regression $\mathrm{R}^{2}$ descriptive statistics.
Descriptive statistics shows the specific of the analyzed sample and provide the support for the hypothesis 1:

1) Total number of company observations is 58 vs 72 in full scope, as far as 14 companies were chosen to be not relevant due to lack of data and its representativeness.

2) Average regression between beta and sentiment is twice higher during high emotional periods [high [low] sentiment period $\mathrm{R}^{2}$ mean is $4.8 \%$ vs. $2.3 \%$ during neutral period.

3) Regression range variate from $0 \%$ up to $\mathrm{R}^{2}=25 \%$ analyzing full period

4) Maximum $\mathrm{R}^{2}=25 \%$ during high sentiment period

Standard deviation $(\sigma)$ is higher during emotional periods [high/ low vs. neutral], grow from $3 \%$ to $4,9 \%$. I.e., grow of variation to the median.

Percentile variation confirm that during neutral sentiment period $\mathrm{R}^{2}$ is lower.

Here we confirm the hypothesis 1 , that sentiment period influences the value of the systematic risk coefficient $(\beta)$ and it depends on highlow period of sentiment, it is proved by the regression analysis and descriptive results. The level of $\mathrm{R}^{2}$ does not allow us to postulate that sentiment is the main antecedent of the systematic risk coefficient, but we see that $\mathrm{R}^{2}$ mean is twice higher during high and low sentiment periods, making a support to the idea that during emotional periods the referent shares follow the volatility of the benchmark market stronger, comparing to the neutral period, so far giving a support to the hypothesis 1 . Our results help to establish the strategy for traders within different emotional periods, for example during high or low sentiment periods is better to follow beta rather than trading against beta could be more profitable during neutral period.

\section{Cluster analysis}

To check the hypothesis 2 we provided a 2-steps K-mean clustering, basing Madhulatha [69] comparative research. Cluster analysis was chosen as method for dividing data into groups that are meaningful. It is used for sentiment dependent company computation and finding its peculiarities. A simple partitional clustering divides data into nonoverlapping groups. A prominent algorithm for clustering is $\mathrm{K}$-means where data are grouped into a predetermined number of clusters specified by user.

We used the following algorithm:

1) We chose 5 clusters for each of sentiment period (full, high, neutral, low).

2) We range clusters in each sentiment period (full, high, neutral, low) by giving the name of " 1 " to the less sentiment affected cluster and " 5 " to the most sentiment affected.

3) We gave weights to each company, weight of 1 to cluster 1 and weight of 5 to cluster 5 , so far weighting them by the level of sentiment dependence, the more value - in the higher cluster company were settled before.

4) We made the second K-mean cluster analysis using the total weights received on the previous step.

5) We form 3 clusters, where "1" cluster name to the group of low affected companies and " 3 " to the most affected. 
The complete results of the step by step cluster process could be found in Appendix 3. We also provide the full list of companies in the Appendix 4 depending on the cluster. Most of the companies got into the low sentiment affected group-25 companies, 7 companies were put into high sentiment affected cluster and 26 into neutral.

Claessens et al. [60] provide a firm specific weakness. He postulates that high level of leverage is the part of firm financial instability. Berkmen et al. [61] showed that countries with more leveraged financial systems, stronger credit growth, and more short-term debt tended to suffer a larger effect on economic activity, showing financial instability. We hypothesis that companies with low level of financial stability have stronger dependence between beta and sentiment, so far reflecting sentiment situation on market and should be inside of the cluster of high sentiment affect companies (cluster " 3 ").

To analyze the accounting and financial stability of each cluster we base our research on the findings of Claessens et al. [60] and Berkmen et al. [61]. We use the ratios of size, financial leverage and other financial rates from Angel [25]:

Current ratio (CR), Financial leverage (FL), Asset turnover ratio (AST), Total debt to assert ratio $\left(\mathrm{LV}_{1}\right)$, Long-term debt to equity $\left(\mathrm{LV}_{2}\right)$, Size $\left(\mathrm{SZ}_{1}\right)$ as natural logarithm to total assets, Income after taxes (IAT), Operational leverage $(\mathrm{OL})$.

In the Table 7 we provide the results of cluster accounting and financial statistics, we have 3 groups of companies with high, neutral and low level of regression between beta and sentiment [70-73]. We provide the mean values for current ratio (CR), financial leverage (FL), asset turnover ratio (AST), total debt to assert ratio $\left(\mathrm{LV}_{1}\right)$, long-term debt to equity $\left(\mathrm{LV}_{2}\right)$ size $\left(\mathrm{SZ}_{1}\right)$ as natural logarithm to total assets, income after taxes (IAT) and operational leverage (OL) by this we are able to define the peculiarities of every cluster.

Analyzed sample in Table 7 provide us following results:

1) High sentiment affected companies have low level of current ratio, that means low ability to pay back its liabilities (debt and accounts payable) $\mathrm{CR}=1.09$

2) High level of AST means low efficiency with which a company of high sentiment is deploying its assets in generating revenue AST $=0.62$

3) High level of FL means that companies are using debt and other liabilities to finance its assets $\mathrm{FL}=3,98 \mathrm{LV}_{1}$ and $\mathrm{LV}$, are high for sentiment affected companies, i.e., that total amount of debt relatively high to assets

4) Sentiment affected companies are using more fixed to variable costs, so far having more operating leverage $\mathrm{OL}=0,12$

5) Comparing to others sentiment affected companies are relatively big on the market, $\mathrm{SZ}_{1}$

6) No special feature regarding to income, profit or EBIT were found.

\begin{tabular}{|c|c|c|c|c|c|c|c|c|c|}
\hline Sentiment affect & Count & CR & FL & AST & $\mathrm{LV}_{1}$ & $\mathbf{L V}_{2}$ & $\mathrm{SZ}_{1}$ & IAT & $\mathrm{OL}$ \\
\hline High [“3”] & 7 & 1.09 & 3.98 & 0.62 & 0.71 & 3.35 & 7.80 & 173.59 & 0.12 \\
\hline Neutral [“2”] & 26 & 1.09 & 3.46 & 1.18 & 0.62 & 1.92 & 7.02 & 320.35 & 0.09 \\
\hline Low [“1”] & 25 & 1.33 & 3.49 & 1.22 & 0.56 & 2.28 & 5.64 & 49.31 & 0.09 \\
\hline Total & 58 & 1.21 & 3.55 & 1.12 & 0.60 & 2.30 & 6.44 & 163.86 & 0.09 \\
\hline
\end{tabular}
(SZ1) as natural logarithm to total assets, Income after taxes (IAT), Operational leverage (OL) between beta and sentiment and proved that relationship between systematic risk coefficient $(\beta)$ and sentiment is stronger in the group of companies with low level of financial stability comparing to the full sample of companies confirming the hypothesis 2 [74]. Group of companies whose beta is stronger affected by sentiment (high" 3 ") keep the features of big unstable companies with not effective financial control, high level of leverage and less possibility to pay debts [75-77].

\section{Conclusion and Limitation}

This paper put the aim to investigate the role that investor sentiment plays in systematic risk. Current research focused on the idea that a firm stock level has the antecedents not only of a fundamental rational environment but at the same time is a part of a human behavior, reflexing personal group narratives and sentiment.

In our research beta $(\beta)$ plays a role of a valid objective and systematic equity risk measure, which allows to calculate the return of capital. Classical Capital Asset Pricing Model (CAPM) defines the variables, which influence on systematic risk coefficient $(\beta)$ from efficient market hypothesis (EMH) point of view, i.e., traders being rational and leaving no space for sentiment existing on the market.

We decided to test if the level of systematic risk depends on the sentiment level and varies within group of different companies. Evidence on the validity of our research will help the stock market players to pay attention to sentiment levels and choose the proper group of companies to invest depending on the period of high-low sentiment and characteristics of chosen company.

We chose the hospitality sector because the importance to variate between industry and country was proved and found that different sectors of economy keep different systematic risk levels. Hospitality covers more than $3 \%$ of US GDP and plays important role in economic power together with reflexing economic trends, we follow the paper using the data set of companies from US tourism industry. In this paper we test 2 hypotheses; the first hypothesis postulate that highlow period of sentiment influence on the value of systematic risk coefficient ( $\beta$ ), i.e., that beta of each company will have different value depending the state of sentiment environment on market. The second hypothesis posits that relationship between systematic risk coefficient and sentiment is stronger in the group of companies with low level of financial stability comparing to the full sample of companies, i.e., that companies with low level of financial stability bearing stronger pressure during emotional explosion on the market. To say the simple words, if sentimental situation on the market aims to the negative or positive extremum, the companies with low level of financial stability will strongly follow market trend comparing to more stable companies.

Our results support all hypothesis, showing that that systematic risk coefficient $(\beta)$ is dependent on high-low period of sentiment. We found that average $\mathrm{R}^{2}$ between beta and sentiment is twice higher during high emotional periods (high (low)) sentiment period, $\mathrm{R}^{2}$ mean
In the Table 7 we grouped the companies by the level of regression is $4.8 \%$ vs. $2.3 \%$ during neutral period. The second hypothesis was 
Citation: Angel K, Plans CM (2018) Systematic Risk Coefficient and Sentiment: Peculiarities of Sentiment Affected Companies in US Tourism Industry. Bus Eco J 9: 378. doi: 10.4172/2151-6219.1000378

also confirmed, companies which are strongly affected by sentiment keep the features of big unstable companies with not effective financial control, high level of leverage and less possibility to pay debts. Our paper also confirm possibility to differentiate companies into different groups due to their reaction on sentiment and it postulate that highlow period of sentiment affect differently on companies from different clusters.

We would like to underline the main finding of the research, we found that:

a) Period of sentiment influence on the value of systematic risk coefficient $(\beta)$,

b) Relationship between systematic risk coefficient and sentiment is stronger in the group of companies with low level of financial stability.

The results of our research is in line with findings found the traders are more likely to be prone to behavioral biases such as overconfidence, which can cause them to under-assess risk during optimistic periods. It also partially in line who hypothesize that periods of optimism attract equity investment by unsophisticated and overconfident traders who under-assess risk.

The limitation of our research could be gathered into 4 main groups - related to data, methodology and framework of the research. More precisely are:

a) The database could be expanded,

b) The other sentiment index could be found due to change in sentiment compounds and other variables chosen,

c) The other ways to measure connection could be used, for example panel threshold regression, time series regression or mean variance analysis, cluster analysis technic might be improved.

d) The other ways to the measure stability, indicators and factors could be used.

This paper shed the light to cross relation of beta and sentiment in the market, our findings expand the knowledge of peculiarities of sentiment affected companies, and provide deeper understanding of risk assessment during different emotional periods of the market. But future researchers should put the effort on the stronger deep dive analysis: we ask them to understand better and find more antecedents of sentiment affected companies, to make a comparative analysis within different sectors of economy and different countries, increase the time factor under consideration, the more important is to understand the route of dependence - is it general sentiment who affect companies or vice versa. This latter investigation would be beneficial to stock market actors, policy makers and researchers seeking to control irrational fluctuation and speculation with its associated impact on the special company or on economy in general.

\section{References}

1. Degutis A, Novickyte $L$ (2014) The efficient market hypothesis: a critical review of literature and methodology. Ekonomika 93: 7-23.

2. Shiller RJ (2013) Capitalism and financial innovation. Financial analyst journa Disasters. New York: Ticker Publishing.

3. Sharpe WF (1964) Capital asset prices: A theory of market equilibrium under conditions of risk. J Financ 19: 425-442.

4. Lintner J (1965) Security prices, risk, and maximal gains from diversification. J Financ 20: 587-615.
5. Markowitz H (1952) Portfolio selection. J Financ 7: 77-91.

6. Damodaran A (2012) Applied corporate finance, Hoboken, NJ: John Wiley \& Sons.

7. Shefrin $H$ (2008) Risk and return in behavioral SDF-based asset pricing model. J Investment Manage 6: 1-18.

8. Ho JC, Hung CHD (2012) Predicting stock market returns and volatility with investor sentiment: evidence from eight developed countries. J Account Financ 12: 49-65.

9. Fama ER, French K (1992) The Cross-Section of Expected Stock Returns. J Financ 47: 427-465.

10. Acharya VV, Pedersen LH (2005) Asset pricing with liquidity risk. J Financ Econ 77: $375-410$.

11. Arfaoui M, Abaoub E (2010) The determinants of systematic risk: International evidence from the macro-finance interface. J Adv Stud Financ 2: 119-141.

12. Morelli D (2012) Security returns, beta, size, and book-to-market equity: Evidence from the Shanghai A-share market. Rev Quant Financ Account 38: 47-60.

13. Driessen J, Lin TC, Phalippou L (2012) A New Method to Estimate Risk and Return of Nontraded Assets from Cash-Flows: The case of Private Equity Funds. J Financ Quant Anal 47: 511-535.

14. Boz G, Menéndez-Plans C, ,Orgaz-Guerrero N (2015) The systematic-risk determinants of the European accommodation and food services industry in the period 2003-2011. Cornell Hospitality Quarterly 56: 1-17.

15. Babenko I, Boguth O, Tserlukevich Y (2016) Idiosyncratic cash flows and systematic risk. J Financ 71: 425-456

16. Nicolau JL, Sellers R (2011) The effect of quality on hotel risk. Tourism Econ 17: $39-52$.

17. Kim H, Kim J, Gu Z (2012) An examination of US hotel firm's risk features and their determinants of systematic risk. Tourism Res 14: 28-39.

18. Lee SK, Jang CS (2012) The real estate risk of hospitality firms: Examining stock-return sensitivity to property values. Int J Hospitality Manage 31: 695-702.

19. Lee CH, Hooy CW (2012) Determinants of systematic financial risk exposures of airlines in North America, Europe and Asia. J Air Trans Manage 24: 31-35.

20. Chen MH (2013) Risk determinants of China's hotel industry. Tourism Econ 19: 77-99.

21. Park SY, Kim SH (2016) Research note: Determinants of systematic risk in the US restaurant industry: a technical perspective. Tourism Econ 22: 621-628.

22. Engle R, Jondeau E, Rockinger M (2015) Systematic Risk in Europe. Rev Financ 19: 145-190.

23. Mar-Molinero C, Menendez-Plans C, Orgaz-Guerrero N (2017) Has the 2008 financial crisis changed the factors determining the systematic risk of shares in the European Hospitality Industry? (2003-2013). J Financ 69: 1377-1409.

24. Foster G, Kasnik R, Sidhu BK (2012) International equity variation: the relative importance of country and industry factors versus company-specific financial reporting information. Account Financ 52: 767-814

25. Angel K, Menéndez-Plans C, Orgaz-Guerrero N (2018) Risk management: comparative analysis of systematic risk and effect of the financial crisis on US tourism industry: Panel data research. Int $\mathrm{J}$ Contemp Hospitality Manage 30: 1920-1938.

26. Park K, Jang S (2014) Hospitality Finance and Managerial Accounting Research. Suggesting and interdisciplinary research agenda. Int J Contemp Hospitality Manage 26: 751-777.

27. Selden GC (1912) Psychology of the Stock Market: Human Impulses Lead To Speculative Disasters.

28. Festinger L, Riecken H (1956) When Prophecy Fails. Minneapolis: University of Minnesota Press.

29. Pratt $J(1964)$ Risk Aversion in the Small and in the Large. Econometrica 32 $122-136$.

30. Tversky A, Kahneman D (1973) Availability: A Heuristic for Judging Frequency and Probability. Cogn Psych 5: 207-232. 
Citation: Angel K, Plans CM (2018) Systematic Risk Coefficient and Sentiment: Peculiarities of Sentiment Affected Companies in US Tourism Industry. Bus Eco J 9: 378. doi: 10.4172/2151-6219.1000378

31. Kahneman D, Knetsch J, Thaler R (1990) Experimental Tests of the Endowment effect and the Coase Theorem. J Polit Econ 98: 1325-1348.

32. Daniel K, Hirshleifer D, Subrahmanyam A (1998) Investor Psychology and Security Market Under- and Overreactions. J Financ 53: 1839-1885.

33. Shleifer A (2003) Inefficient Markets: An Introduction to Behavioral Finance. Oxford: OUP.

34. Shefrin H (2002) Beyond Greed and Fear: Understanding Behavioral Finance and the Psychology of investing. Oxford: OUP

35. Baker M, Wurgler J (2006) Investor Sentiment and the Cross-Section of Stock Returns. J Financ 61: 1645-1680.

36. Shefrin H, Statman M (1994) Behavioral Capital Asset Pricing Theory. J Financ Quant Anal 29: 323-349.

37. Antoniou C, Doukas J, Subrahmanyam A (2012) Cognitive dissonance, sentiment and Momentum. J Financ Quant Anal 48: 245-275.

38. Bandopadhyaya A, Jones AL (2005) Measuring investor sentiment in equity markets. J Asset Manage 7: 208-215.

39. Hwang S, Salmon S (2006) Sentiment and Beta Herding, paper presented to the Behavioral Finance and Market Efficiency Workshop, University of Warwick.

40. Chang EC, Yan L, Ren J (2008) Investor Overconfidence and the Increase in Idiosyncratic Risk, working paper, University of Hong Kong.

41. Hachicha N, Bouri A (2008) Behavioral Beta and Asset Valuation Models. In Res J Financ Econ.

42. Ling DC, Naranjo A, Scheick B (2010) Investor Sentiment and Asset Pricing in Public and Private Markets. RERI WP 170.

43. Finter $P$, Niessen-Ruenzi A, Ruenzi S (2010) The impact of investor sentiment on the German stock market. Zeitschrift für Betriebswirtschaft 82: 133-163.

44. Boido C, Fasano A (2011) CAPM with Sentiment. J Financ Manage, University of Siena, preliminary draft.

45. Stambaugh R, Yu J, Yuan Y (2012) The short of it: Investor sentiment and anomalies. J Financ Econ 104: 288-302.

46. Chung SL, Hung $\mathrm{CH}$, Yeh $\mathrm{CY}$ (2012) When does investor sentiment predict stock returns? J Empirical Financ 19: 217-240.

47. Antoniou C, Subrahmanyam A, Doukas JA (2013) Investor Sentiment and Beta Pricing, Working Paper.

48. Chow KV, Klein RF (2013) Sentiment Effect and Market Portfolio Inefficiency. Int J Bus Econ 8: 139-146.

49. Shefrin H (2014) Investors' Judgments, Asset Pricing Factors and Sentiment. Eur Financ Manage 21: 205-227.

50. Fong WM, Toh B (2014) Investor sentiment and the MAX effect. J Bank Financ 46: 190-201.

51. Yu J, Yuan $Y(2011)$ Investor sentiment and the mean-variance relation. $J$ Financ Econ 100: 367-381.

52. McLean R, Zhao M (2014) The business cycle, investor sentiment and costly external finance. J Financ 69: 1377-1409.

53. Jurek J, Stafford E (2015) The cost of capital for alternative investment. J Financ 70: 2185-2226.

54. Habib A, Hasan M (2017) Firm life-cycle, corporate risk-taking and investor sentiment. Account Financ 57: 465-497.
55. Deeney P, Cummins M, Dowling M (2015) Sentiment in oil markets. Int Rev Financ Anal 39: 179-185.

56. Baker M, Wurgler J, Yuan Y (2012) Global, local and contagious investor sentiment. J Financ Econ 104: 272-287.

57. Antoniou C, Doukas J, Subrahmanyam A (2015) Investor sentiment, beta and cost of equity capital. Manage Sci 62 : 347-367.

58. Frugier A (2016) Returns, volatility and investor sentiment: evidence from European stock market. Res Int Bus Financ 38: 45-55.

59. Cederburg S, O'Doherty M (2016) Does it pay to bet against beta? On the conditional performance of beta anomaly. J Financ 71: 737-774.

60. Claessens S, Djankov S, Xu L (2000) Corporate performance in East Asian financial crisis. The World Bank Res Obser 15: 23-46.

61. Berkmen P, Gelos RG, Rennhack R, Walsh JP (2012) The global financial crisis: explaining cross-country differences in the output impact. J Int Money Financ 31: 42-59.

62. Hollenstein H (2003) Innovation modes in SWISS service sector: a cluster analysis based on firm level. Res Policy 32: 845-863.

63. Tola V, Lilo F, Gallegati M, Mantegna R (2008) Cluster analysis for portfolio optimization. J Econ Dynam Control 32: 235-258.

64. Kadilli $H$ (2003) Predictability of stock returns of financial companies and the role of investor sentiment: A multi-country analysis. J Financ Stabil 21: 26-45.

65. Wold S, Esbensen K, Geladi P (1987) Principal component analysis Chemometr Intell Lbortory Syst 2: 37-52.

66. Abdi H, Williams LJ (2010) Principal component analysis. WIREs Comp Stat 2: 433-459.

67. Leech N, Barrett K, Morgan G (2007) SPSS for intermediate statistics Routledge, New-York.

68. Cornell B, Landsman WR, Stubben S (2017) Accounting Information, investor sentiment and market pricing. J Law Financ Account 2: 325-345.

69. Madhulatha T (2012) An overview on clustering methods. J Eng 2: 719-725.

70. Barberis N, Greenwood R, Jin L, Shleifer A (2015) X-CAPM: An extrapolative capital asset pricing model. J Financ Econ 115: 1-24.

71. Chong J, Philips G (2012) Measuring risk for cost of capital: the downside beta approach. J Corp Treasury Meas 4: 344-352.

72. Huang D, Jiang F, Tu J, Zhou G (2015) Investor sentiment aligned: a powerful predictor of stock return. Rev Financ Stud 28: 791-837.

73. Kearney J, Liu G (2014) Textual sentiment in finance: a survey of methods and models. Int Rev Financ Anal 33: 171-185.

74. Ni Z, Wang D, Xue W (2015) Investor sentiment and its nonlinear effect on stock returns - New evidence from the Chinese stock market based on pane quantile regression model. Econ Model 50: 266-274.

75. Shen J, Yu J, Zhao S (2017) Investor sentiment and economic forces. J Monetary Econ 86: 1-21.

76. Sibley S, Wang Y, Xing Y, Zhang X (2016) The information content of sentiment index. J Bank Financ 62: 164-179.

77. Wahyudin I, Djatna T, Kusuma W (2016) Cluster Analysis for SME Risk Analysis Documents Based on Pillar K-Means, Telkomnika 14: 674-683. 